\title{
Glycosylated Hemoglobin and Protein Levels in Normal and Diabetic Pregnancies
}

\author{
Mohamed M. Elseweidy, Ph.D. \\ Hossam E. Fadel, M.D., F.A.C.O.G. \\ Edathara C. Abraham, Ph.D.
}

DOI: http://dx.doi.org/10.5915/17-2_3-12756

\begin{abstract}
:
The glycosylated fractions of hemoglobin i.e. Glycohemoglobin (GlycoHb) and of the plasma proteins i.e. Glycoprotein (GlycoPR) levels were quantitated using an affinity chromatographic technique in the cord and maternal blood of normal (Group I), White's Class A diabetic (Group II), and insulin-dependent diabetic (Group III) women. There was a significant increase of GlycoHb and GlycoPR levels in Group III compared to Group I neonates. Maternal GlycoHb but not GlycoPR levels were significantly higher in Group III patients. Maternal and cord blood GlycoHb and GlycoPR levels in Class A diabetics were not different from those levels in the normal group. We conclude that the fetuses of insulin-dependent diabetic mothers are hyperglycemic in utero.
\end{abstract}

Key Words: Glycosylation, fetal hemoglobin, glycosylated hemoglobin, glycosylated protein, diabetes mellitus, normal pregnancy, and diabetic pregnancy.

\section{Introduction}

Several minor hemoglobins (Hbs) can be separated chromatographically from adult red cell lysates using cation exchange chromatographic techniques and are designated as $\mathrm{HbA}_{\mathrm{la}}, \mathrm{HbA}_{\mathrm{la} 2}, \mathrm{HbA}_{\mathrm{lb}}$ andHbA $\mathrm{H}_{\mathrm{lc}}$, the latter being the major subfraction., ${ }^{1,3} \mathrm{HbA}_{\mathrm{Ic}}$ is formed by the reaction of the $\alpha$ chain amino terminus of $\mathrm{HbA}_{\circ}$ (major hemoglobin) with glucose, whereas $\mathrm{HbA}_{\mathrm{la} 1}$ and $\mathrm{HbA}_{\mathrm{la} 2}$ are formed by the reaction of fructose-1,6-diphosphate and glucose-6-phosphate, respectively. $\mathrm{HbA}_{\mathrm{Ib}}$ is a glycosylated $\mathrm{Hb}$ whose identity is unknown. However, other glycosylated hemoglobins that are formed by glycosylation of the $\alpha$ chain amino terminus and $\varepsilon$-amino groups of certain lysyl residues on both chains are not normally separated by cation exchange chromatography technique.5 Glycosylation of $\mathrm{Hb}$ occurs by a nonenzymatic reaction that is continuous throughout the life-span of the red blood cell. ${ }^{6}$ It follows that glycosylated $\mathrm{Hb}$ levels will reflect the time-averaged blood glucose level over a period of 8-12 weeks. 7 This has led to increasing interest of the clinicians in the study of these levels in relation to diabetes mellitus. $4,7,8$ It has been shown that $\mathrm{HbA}_{\mathrm{I}}\left(\mathrm{A}_{\mathrm{la}+\mathrm{b}+\mathrm{c}}\right)$ level is increased in diabetes mellitus and that the magnitude of increase is related to the degree of metabolic control.4, 7, 8 This increase of $\mathrm{HbA}_{1}$ was also reported in diabetic pregnant women. 9

From the Department of Cell and Molecular Biology and Department of Obstetrics and Gynecology Maternal-Fetal Medical Section, Medical College of Georgia, Augusta, Georgia

Address all correspondence to Hossam E. Fadel, M.D. Department of Obstetrics \& Gynecology, Maternal-Fetal Medical Section, Medical College of Georgia, Augusta, Georgia 30912
Several minor $\mathrm{Hbs}$, namely $\mathrm{HbF}_{\mathrm{la}}, \mathrm{HbF}_{\mathrm{la} 2}, \mathrm{HbF}_{\mathrm{lb}}$, and $\mathrm{HbF}_{\mathrm{lc}}$ were separated from cord blood cell lysates using similar cation exchange chromatographic techniques. $\mathrm{HbF}_{\mathrm{lc}}$ contains $\gamma$ chains mostly acetylated, but it contains minor glycosylated $\mathrm{Hb}$ as well. ${ }^{2,3}$ In a previous study, we have shown that the level of $\mathrm{HbF}_{\mathrm{ic}}$ is increased in newborns of diabetic mothers. This increase was postulated to reflect a higher time-averaged fetal blood glucose levels in the 6-8 weeks prior to delivery. However, it was not possible to determine whether the increase of $\mathrm{HbF}_{\mathrm{lc}}$ was due to an increase in the acetylated or the glycosylated fraction..$^{10}$

The specific interaction of boronic acid ligands with 1,2-cis-diol compounds resulted in affinity chromatographic techniques for the separation of some glycoproteins." Affinity chromatographic methods utilizing m-amino-phenylboronic acid immobilized on agarose have been recently introduced to quantitate the total glycosylated fraction of $\mathrm{Hb}$ i.e. Glycohemoglobin (GlycoHb) even in the presence of $\mathrm{HbF}$ and various abnormal hemoglobins.12, ${ }^{13}$ This technique is therefore particularly suited for the quantitation of GlycoHb in cord blood.

The purpose of this study was to use the new technique to measure the levels of GlycoHb and GlycoPR in normal and diabetic mothers and their newborns and to find out if there are any significant differences in these levels between the newborns of normal and diabetic mothers. This would give a more accurate indication of the time-averaged blood glucose levels in utero in these pregnancies.

\section{Materials and Methods}

Forty-eight pregnant women participated in this study. Informed consent was obtained from all patients. They were classified into three groups: Group I, 
twenty normal women with a normal glucose screening test i.e., a blood glucose value $<130 \mathrm{mg} / \mathrm{dl}$, one hour after a $50 \mathrm{gm}$ glucose load; ${ }^{14}$ Group II, twenty women with an abnormal oral glucose tolerance test i.e., White's Class A diabetics who did not require insulin therapy. Group III, eight women with insulindependent diabetes mellitus (IDDM) of whom seven were Class B, and one was Class C. The management of the diabetic patients was according to the routine protocol in our institution. 14

Samples of blood were collected from mothers at the time of their admission in, or induction of labor, and from the cord at delivery. Blood was collected into tubes containing ethylenediaminetetracetic acid (EDTA) and stored at $4^{\circ} \mathrm{C}$. Within 24 hours the red cells were separated from the plasma by centrifugation and washed three times with isotonic saline. Both the cells and the plasma were used immediately for GlycoHb and GlycoPR determinations.

Microcolumns* prepacked with the affinity gel (m-aminophenylboronic acid) immobilized on agarose, and supplied reagents were used. For GlycoHb determination, $50 \mu \mathrm{l}$ aliquot of the cells suspended in saline were lyzed with $400 \mu \mathrm{l}$ of the sample preparation reagent and $100 \mu \mathrm{l}$ of the lysate were applied to the column and developed at $25^{\circ} \mathrm{C}$. The non-GlycoHb fraction was eluted first with the first fraction elution agent (Solution II) or $0.05 \mathrm{M}$ HEPES buffer, adjusted to $\mathrm{pH} 8.5$ with $\mathrm{HCl}$ and containing $10 \mathrm{mM} \mathrm{MgCl}_{2}$ and $0.02 \%$ sodium azide. The GlycoHb fraction (bound to the gel) was eluted with the second fraction elution buffer or $100 \mathrm{mM}$ sorbitol. The absorbance of each fraction was read at 415 $\mathrm{nm}$ in a Beckman spectrophotometer and the percentage of GlycoHb was calculated. For GlycoPR determination, $500 \mu \mathrm{l}$ of plasma was mixed with 500 $\mu \mathrm{l}$ of first fraction elution agent. A $400 \mu \mathrm{l}$ aliquot of the diluted sample was applied to the column. The Glyco and non-GlycoPR fractions were eluted in the same way as before. One hundred $\mu \mathrm{l}$ of each fraction was mixed separately with $4 \mathrm{ml}$ of diluted protein reagent supplied by the manufacturer.* Colors developed were read at $595 \mathrm{~nm}$ and the percentage of GlycoPR was calculated.

The results of the determinations were analyzed statistically using one-way analysis of variance (Bartlett's test).

*Glyc-Affin system, Isolab Inc., Akron, Ohio

\section{Results}

The Clinical data of the patients are shown in Table 1. The results of GlycoHb and GlycoPR determinations in the maternal and cord blood in all study groups are given in Tables 2 and 3 . It is to be noted that cord blood levels were always lower than the maternal blood levels in both the normal and diabetic groups. Maternal GlycoHb in Group III was significantly higher than in the normal group ( $\mathrm{p}<0.005$ ),
TABLE I. CLINICAL DATA OF STUDY PATIENTS

$\begin{array}{lccc} & \begin{array}{c}\text { GROUP I } \\ \mathrm{N}=20\end{array} & \begin{array}{c}\text { GROUP II } \\ \mathrm{N}=20\end{array} & \begin{array}{c}\text { GROUP III } \\ \mathrm{N}=8\end{array} \\ & 23.1 \pm 5.8 * & 25.5 \pm 5.4 & 29.1 \pm 5.5 \\ \text { Age (ys) } & 2.2 \pm 1.6 & 3.1 \pm 1.8 & 4.1 \pm 1.7 \\ \text { Gravidity } & & & \\ \text { Gest. Age at } & & 38.2 \pm 2.4 & 38.3 \pm 1.0 \\ \quad \text { Delivery (wks) } & 39.3 \pm 1.0 & 3447 \pm 791 & 3506 \pm 427 \\ \text { Birth Weight (8) } & 3270 \pm 410 & & \\ \text { - Mean } \pm \text { S.D. } & & & \end{array}$

TABLE 2. GLYCOHEMOGLOBIN LEVELS * IN MATERNAL AND CORD BLOOD OF THE STUDY PATIENTS

\begin{tabular}{|c|c|c|}
\hline & $\begin{array}{l}\text { MATERNAL. } \\
\text { BLOOD }\end{array}$ & $\begin{array}{l}\text { CORD } \\
\text { BLOOD }\end{array}$ \\
\hline $\begin{array}{l}\text { Normal Group, } \\
\qquad \mathrm{N}=20\end{array}$ & $\begin{array}{l}7.0 \pm 0.6 * * \\
(5.9-8.0)\end{array}$ & $\begin{array}{c}4.7 \pm 0.7 \\
(3.3 \cdot 5.8)\end{array}$ \\
\hline $\begin{array}{l}\text { Class A Diabetes, } \\
\qquad \mathrm{N}=20\end{array}$ & $\begin{array}{c}6.4 \pm 1.2 \\
(4.8-8.4)\end{array}$ & $\begin{array}{r}4.4 \pm 1.2 \\
(3-7.6)\end{array}$ \\
\hline $\begin{array}{l}\text { Insulin Dependent } \\
\text { Diabetes } \\
\mathrm{N}=8\end{array}$ & $\begin{array}{c}8.9 \pm 0.9 \\
(7.6-9.7)\end{array}$ & $\begin{array}{c}6.2 \pm 0.7 \\
(4.9 \div 6.8)\end{array}$ \\
\hline
\end{tabular}

- Percentage of total $\mathrm{Hb}$

$*$ Mean + S.D. and range

TABLE 3, GLYCOPROTEIN LEVELS* IN MATERNAL AND CORD BLOOD OF THE STUDY PATIENTS

\begin{tabular}{|c|c|c|}
\hline & $\begin{array}{l}\text { MATERNAL. } \\
\text { BLOOD }\end{array}$ & $\begin{array}{l}\text { CORD } \\
\text { BLOOD }\end{array}$ \\
\hline $\begin{array}{l}\text { Normal Group, } \\
\qquad N=20\end{array}$ & $\begin{array}{r}12.8 \pm 1.4 * * \\
(10.0 \pm 15.4)\end{array}$ & $\begin{array}{l}8.8 \pm 1.6 \\
(6.4 \pm 12.8)\end{array}$ \\
\hline $\begin{array}{l}\text { Class A Diabetes, } \\
\qquad \mathrm{N}=20\end{array}$ & $\begin{array}{l}10.8 \pm 2.5 \\
(4.6-15.9)\end{array}$ & $\begin{array}{l}9.0 \pm 1.9 \\
(6.1-11.7)\end{array}$ \\
\hline $\begin{array}{l}\text { Insulin Dependent } \\
\text { Diabetes } \\
\mathrm{N}=8\end{array}$ & $\begin{array}{l}14.3 \pm 3.9 \\
(8.6-19.4)\end{array}$ & $\begin{array}{c}13.4 \pm 3.7 \\
(10.0-19.1)\end{array}$ \\
\hline
\end{tabular}

TABLE 4. GLYCOHEMOGLOBIN AND GLYCOPROTEIN LEVELS IN MATERNAL BL.OOD OF THE STUDY GROUPS

$\begin{array}{cccc} & \begin{array}{c}\text { GROUP I } \\ \mathrm{N}=20\end{array} & \begin{array}{c}\text { GROUP II } \\ \mathrm{N}=20\end{array} & \begin{array}{c}\text { GROUP III } \\ \mathrm{N}=8\end{array} \\ \text { GlycoHb } & 7.0 \pm 0.6^{*} & 6.4 \pm 1.2 & 8.9 \pm 0.9+ \\ & (5.9=8.0) & (4.8-8.4) & (7.6=9.7) \\ \text { GlycoPR } & 12.8 \pm 1.4 & 10.8 \pm 2.5 & 14.3 \pm 3.9 \\ & (10.0-15.4) & (4.6-15.9) & (8.6=19.4)\end{array}$

- Mean \pm S.D. and range

+ Significantly higher than controls, $\mathrm{p}<0.001$

TABLE S. GLYCOHEMOGLOBIN AND GLYCOPROTEIN LEVELS IN CORD BLOOD OF THE STUDY GROUPS

$\begin{array}{cccc} & \begin{array}{c}\text { GROUP 1 } \\ \mathrm{N}=20\end{array} & \begin{array}{c}\text { GROUP II } \\ \mathrm{N}=20\end{array} & \begin{array}{c}\text { GROUP III } \\ \mathrm{N}=8\end{array} \\ \text { GlycoHb } & 4.7 \pm 0.7 * & 4.6 \pm 1.2 & 6.2 \pm 0.74 \\ & (3.5-5.8) & (3.0-7.6) & (4.9-6.8) \\ \text { GlycoPR } & 8.8 \pm 1.6 & 9.0 \pm 1.9 & 13.8 \pm 3.7+1 \\ & (6.4-12.8) & (6.1-11.7) & (10.0-19.1)\end{array}$

- Mean \pm S.D. and range

† Significantly higher than controls, $p=<0.001$

It Significantly higher thap controls, $\mathrm{p}=\langle 0.005$

while the increase in GlycoPR levels was insignificant. The levels in Class A diabetic women were not different from the normal group (Table 4). Cord blood GlycoHb and GlycoPR levels in Group III neo- 
nates were significantly higher than in the normal group ( $p<0.005$ ). On the other hand, there was no significant difference in cord blood GlycoHb or GlycoPR between Class A diabetics and the normal group (Table 5).

\section{Discussion}

We found that in the normal group GlycoHb levels were lower in the newborns than in their own mothers $(4.7 \pm 0.7 \%$ vs. $7.0 \pm 0.6 \%)$ confirming previous findings. ${ }^{12}$ The decreased GlycoHb levels in the newborns may be due to a shorter red cells survival, 15 and lower mean glucose blood levels in fetuses compared to adults. Another possibility is that $\mathrm{HbF}$ is glycosylated less readily than $\mathrm{HbA}$. However, the results of previous in utero glycosylation studies, ${ }^{16}$ and normal levels of GlycoHb reported earlier in a homozygote for hereditary persistence of fetal hemoglobin do not support this. ${ }^{12}$ It is noteworthy that GlycoPR levels were also significantly lower in the newborns than in their mothers, probably reflecting lower mean fetal blood glucose levels. Cord blood GlycoHb and GlycoPR levels were also lower than the corresponding maternal levels in both Class $\mathrm{A}$ and insulin dependent diabetics. Maternal GlycoHb, but not GlycoPR levels were significantly higher in Group III patients, while neither was elevated in Class A diabetics, as compared to controls. This suggests that:

1. GlycoHb levels are probably more sensitive than GlycoPR levels in reflecting changes in average blood glucose levels.

2. That insulin dependent diabetics have - on the average - higher blood glucose levels than Class A diabetics.

We previously reported an elevated $\mathrm{HbF}_{\mathrm{lc}}$ as determined by ion exchange chromatography in the newborns of insulin dependent mothers. ${ }^{10}$ Using this technique, it was not possible to determine whether this increase was due to an increase in the glycosylated or acetylated fraction of $\mathrm{HbF}_{\mathrm{lc}}$. In addition, the total GlycoHb including $\mathrm{Hb}$ glycosylated at sites other than the $\beta$ chain amino terminus could not be determined by this ion exchange chromatographic technique. Utilizing the new affinity chromatographic technique, we found that GlycoHb and GlycoPR are significantly elevated in the newborns of insulindependent diabetic mothers. GlycoPR and GlycoHb levels are believed to reflect the time-averaged blood glucose concentration in the preceding 2 to 3 weeks or months, respectively. The difference is due to the relatively high turnover rate of albumin which has a half-life in plasma of about 17 days. ${ }^{18}$ Our results indicate that the fetuses of IDDM mothers had mean blood glucose values higher than fetuses of normal mothers. On the basis of a normal GlycoHb $(6.4 \%)$ and GlycoPR $(10.8 \%)$ levels, White's Class A diabetics must have been well controlled which explains why the GlycoHb and GlycoPR levels of their newborns were not different from the newborns of normal mothers.

Fetal macrosomia in diabetic pregnancies has been attributed to fetal hyperglycemia that is secondary to maternal hyperglycemia and consequent fetal hyperinsulinemia (Pedersen Theory). ${ }^{17}$ Direct evidence for this has been lacking since it is not possible to determine fetal blood glucose levels during pregnancy. The results of this study provide indirect evidence of the presence of higher than average fetal blood glucose levels in insulin-dependent diabetic pregnancies. This lends further support to Pedersen Theory.17

\section{References}

1. McDonald M, Shapiro R, Bleichman, et al: Glycosylated minor components of human adult hemoglobin. J. Biol. Chem. 253: 2327, 1978.

2. Abraham EC: Glycosylated minor components of human fetal hemoglobin: Chromatographic separation, identification and functional characterization. Biochem. Biophys. Acta 677:168, 1981.

3. Abraham EC, Cope ND and Braziel NN: On the chromatographic heterogeneity of human fetal hemoglobin. Biochem. Biophys. Acta 577:159, 1979.

4. Bunn HF, Gabbay KH and Gallop PM: The glycosylation of hemoglobin. Relevance to diabetes mellitus. Science 200:21, 1978.

5. Shapiro R, McManus MJ, Zalut C, et al: Sites of nonenzymatic glycosylation of human hemoglobin A. J. Biol. Chem. 225:3120, 1980.

6. Bunn HF, Haney DN, Kamino, et al: The biosynthesis of



7. Gonen B, Rubenstein H, Rochman H, et al: Hemoglobin A: An indicator of the metabolic control of diabetic patients. Lancet 2:734, 1977.

8. Abraham EC, Huff TA, Cope ND, et al: Determination of glycosylated hemoglobins $\left(\mathrm{HbA}_{1}\right)$ with a new microcolumn prodecure: Suitability of the technique for assessing the clinical management of diabetes mellitus. Diabetes 27:931, 1978.

9. Fadel HE, Hammond SD, Huff TA, et al: Glycosylated hemoglobin in normal pregnancy and gestational diabetes mellitus. Obstet. Gynecol. 54:322, 1979.

10. Fadel HE, Reynolds A, Stallings M, et al: Minor (glycosylated) hemoglobins in cord blood of infants of normal and diabetic mothers. Am. J. Obstet. Gynecol. 139:397, 1981.

11. Weith H, Weibers J, and Gilham P: Synthesis of cellulose derivatives containing the dihydroxyboryl group and a study of their capacity to form specific complexes with sugars and nucleic acid components. Biochem. 9:4396, 1970.

12. Abraham EC, Perry RE and Stallings M: Application of affinity chromatography for separation and quantitation of glycosylated Hb. J. Lab. Clin. Med. 102:187, 1982.

13. Abraham EC, Stallings M, Abraham A, et al: Affinity chromatographic quantitation of glycosylated hemoglobin in newborn infants. Hemoglobin 7(5):449, 1983.

14. Fadel HE and Hammond SD: Diabetes mellitus and pregnancy: Management and results. J. Reprod. Med. 27:56, 1982.

15. Pearson HA: Life span of the fetal red blood cell. J. Pediat. $70: 166,1967$.

16. Abraham EC, Stallings M, Cameron BF, et al: Minor hemoglobins in sickle cell heterozygotes and homozygotes with and without diabetes. Biochem. Biophys. Acta 625:109, 1980.

17. Pedersen J: The Pregnant Diabetic and Her Newborn, 2nd Ed. Williams \& Wilkins Co., p. 211, Baltimore 1977. 